\title{
THE USE OF SATELLITE DATA IN THE OPERATIONAL 3D COUPLED ECOSYSTEM MODEL OF THE BALTIC SEA (3D CEMBS)
}

\author{
Artur Nowicki, M. Sc. \\ Maciej Janecki, M. Sc. \\ Mirosław Darecki, Assoc. Prof. \\ Piotr Piotrowski, Ph. D. \\ Lidia Dzierzbicka-Głowacka, Assoc. Prof. \\ Institute of Oceanology, Polish Academy of Sciences, Poland \\ * Maritime Institute in Gdańsk, Poland
}

\begin{abstract}
The objective of this paper is to present an automatic monitoring system for the 3D CEMBS model in the operational version. This predictive, eco hydrodynamic model is used as a tool to control the conditions and bio productivity of the Baltic sea environment and to forecast physical and ecological changes in the studied basin. Satellite-measured data assimilation is used to constrain the model and achieve higher accuracy of its results.

3D CEMBS is a version of the Community Earth System Model, adapted for the Baltic Sea. It consists of coupled ocean and ice models, working in active mode together with the ecosystem module. Atmospheric forecast from the UM model (Interdisciplinary Centre for Mathematical and Computational Modelling of the Warsaw University) are used as a forcing fields feed through atmospheric data model. In addition, river inflow of freshwater and nutrient deposition from 71 main rivers is processed by land model. At present, satellite data from AQUA MODIS, processed by the SatBaltyk project Operational System are used for the assimilation of sea surface temperature and chlorophyll a concentration. In the operational mode, 48-hour forecasts are produced at six-hour intervals, providing a wide range of hydrodynamic and biochemical parameters.
\end{abstract}

Keywords: Baltic, ecosystem, model, satellite, assimilation

\section{INTRODUCTION}

The Baltic Sea is a semi-enclosed, shelf sea. It is exposed to the influence of a number of changing environmental conditions such as atmospheric conditions, inflows of saline ocean waters from the North Sea, freshwater inflows from rivers rich in biogenic substances. Vertical stratification of the Baltic Sea is very strong and changes substantially over the year. All this makes modelling of this region a complicated problem. Even taking into account all these factors, using open boundary conditions, accurate vertical parameterization and forcing fields from state of the art weather forecasting models does not guarantee that the eco hydrodynamic model will be able to reflect the actual state of the environment. This is one of the most important reasons why the assimilation of satellite-measured data must be used in order to constrain the model and produce high accuracy results. 3D CEMBS is a coupled ecosystem model, which main task is to produce short term, 3-dimmensional forecasts of main hydrodynamic and biochemical parameters of the Baltic Sea. It uses Cressman assimilation scheme [2], which is computationally very efficient, but at the same time its accuracy remains satisfactory. Satellite data used for the assimilation is measured by MODIS device installed on the AQUA satellite. Results from this model are used in the SatBałtyk project [10], [11] as well as are presented at model's website - www.cembs.pl. These results of the model cover historical data archived since 2010 till present, as well as 48-hours forecasts updated four times a day.

\section{D CEMBS MODEL}

The 3D CEMBS model is based on a CESM1.0 (Community Earth System Model) and was adapted to the Baltic Sea region. Its main components are coupled ocean and ice models working in an active mode, calculating hydrodynamic results, together with an ecosystem model responsible for calculating biological and chemical parameters.

Ocean model is based on a POP (Parallel Ocean Program) code [9]. It is a z-level coordinates, general circulation ocean model that solves the 3 -dimentional primitive equations for stratified fluid using the hydrostatic and Boussinesq approximations. Sea ice model is based on a CICE (Community Ice CodE). It uses an elastic-viscous-plastic ice rheology [3]. 


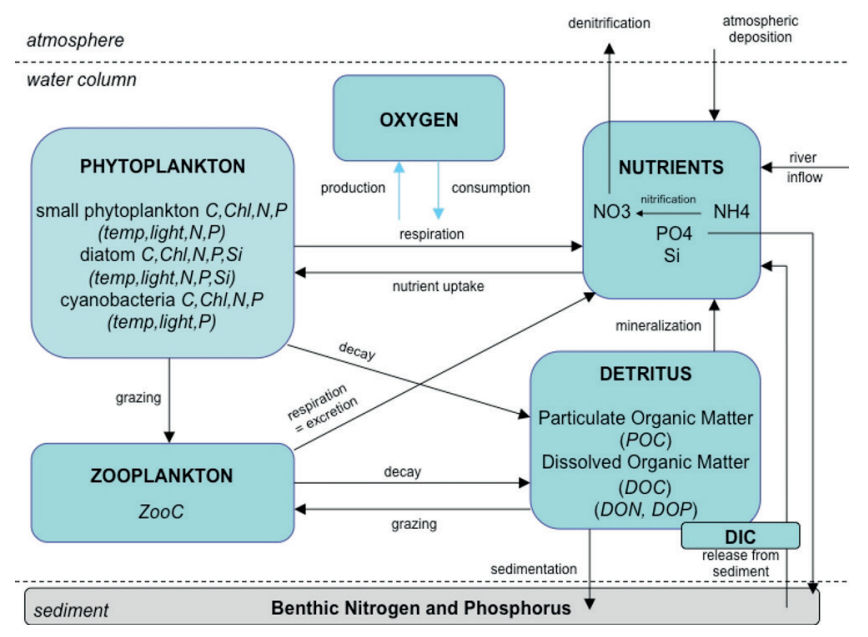

Fig. 1. Ecosystem model block diagram

Ecosystem model, presented on Fig. 1 is based on an intermediate complexity marine ecosystem model for the global domain [7] and consists of 11 main components: zooplankton, small phytoplankton, large phytoplankton, summer species, one detrital class, oxygen and the nutrients: nitrate, phosphate, ammonium and silicate.

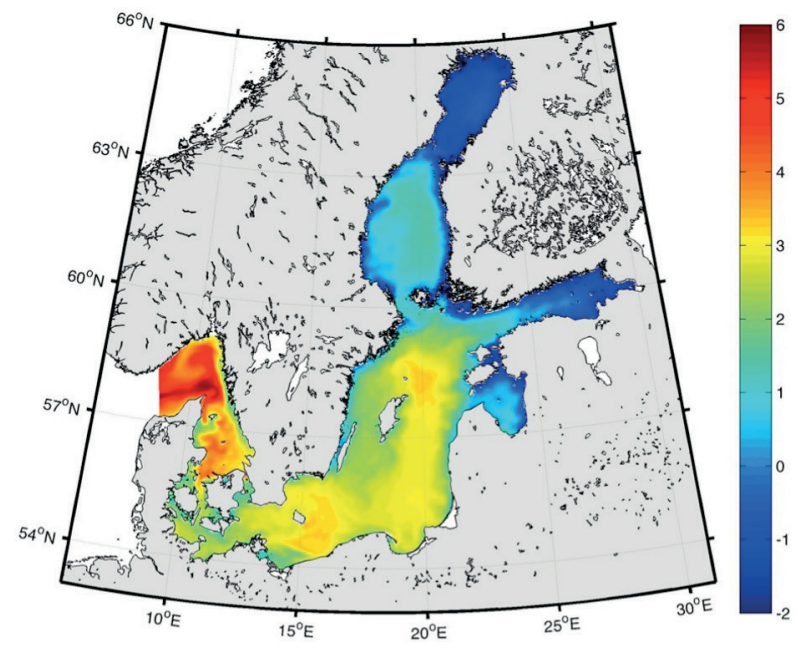

Fig. 2. Model domain with surface layer temperature

In the operational mode, 3D CEMBS is configured at horizontal resolution of $1 / 48 \mathrm{o}$, which is ca. $2 \mathrm{~km}$. Vertically model grid has 21 layers. The thickness of the first four layers is $5 \mathrm{~m}$ and it grows with depth. Model domain is shown in Fig. 2. Atmospheric data from forecasts and mean values of nutrient deposition and freshwater inflow from rivers are feed through data modules. The atmospheric data, which are used as forcing fields, are calculated by the weather forecast model, which is being developed in the Interdisciplinary Centre for Mathematical and Computational Modelling of the Warsaw University. River discharge data are historical, daily averaged values from the Balt-HYPE model of SMHI and the nutrient deposition data are monthly averaged. Discharge from 71 main rivers of the Baltic Sea basin was included. Satellite data used for assimilation are sea surface temperature and chlorophyll a concentration measured by MODIS [1]. They are at spatial resolution of $1 \mathrm{~km}$. Fig. 3 present the scheme of the 3D CEMBS model configuration. The model provides hydrodynamic parameters: water temperature, salinity, sea surface height, current velocity and direction, parameters of sea ice: temperature, concentration and thickness and biochemical parameters such as: dissolved oxygen, concentration of chlorophyll a, phytoplankton, zooplankton and nutrients. Detailed description of hydrodynamic and ecosystem modules as well as the operational mode is presented in Dzierzbicka-Głowacka et al. [4], [5], [6].

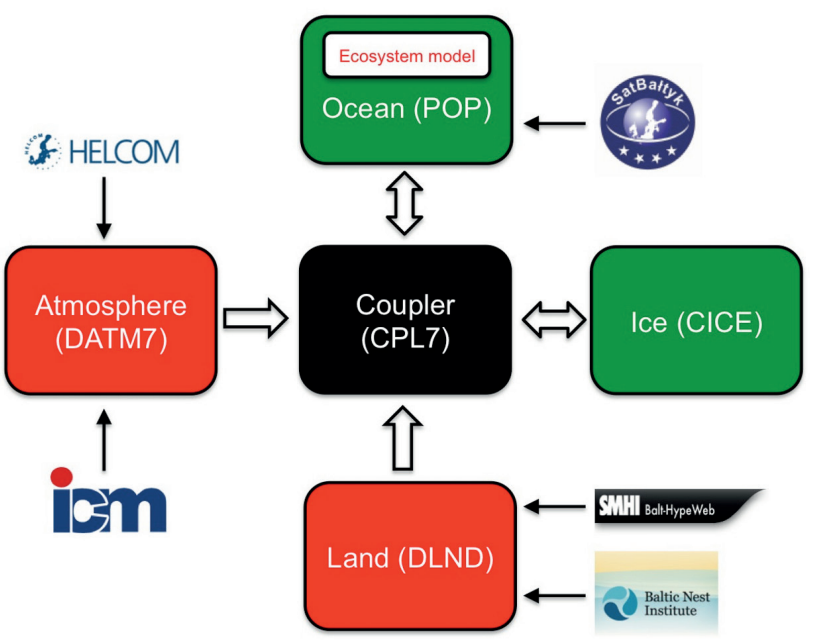

Fig. 3. 3D CEMBS block diagram

\section{OPERATIONAL SYSTEM}

Currently the 3D CEMBS model is running in an operational mode that is fully automated and controlled by specially designed system. In current configuration it provides a 48 -hour forecasts every six hours. Forecasts are available with 1-hour step and archival data are stored with 6-hour step. The system consists of modules that are responsible for the subsequent steps as shown on Fig. 4. First input data such as weather forecast results, satellite data and river discharge data are gathered. All data are then interpolated to model grid and additional parameters are calculated. Then, if present, satellite data are assimilated and the forecast is calculated. Afterwards system prepares output data to be presented on a model's webpage, www. cembs.pl, and prepares archives forecast's results. Surface parameters are then properly processed and transferred to SatBałtyk database server, where they can be accessed through SatBałtyk project webpage. 


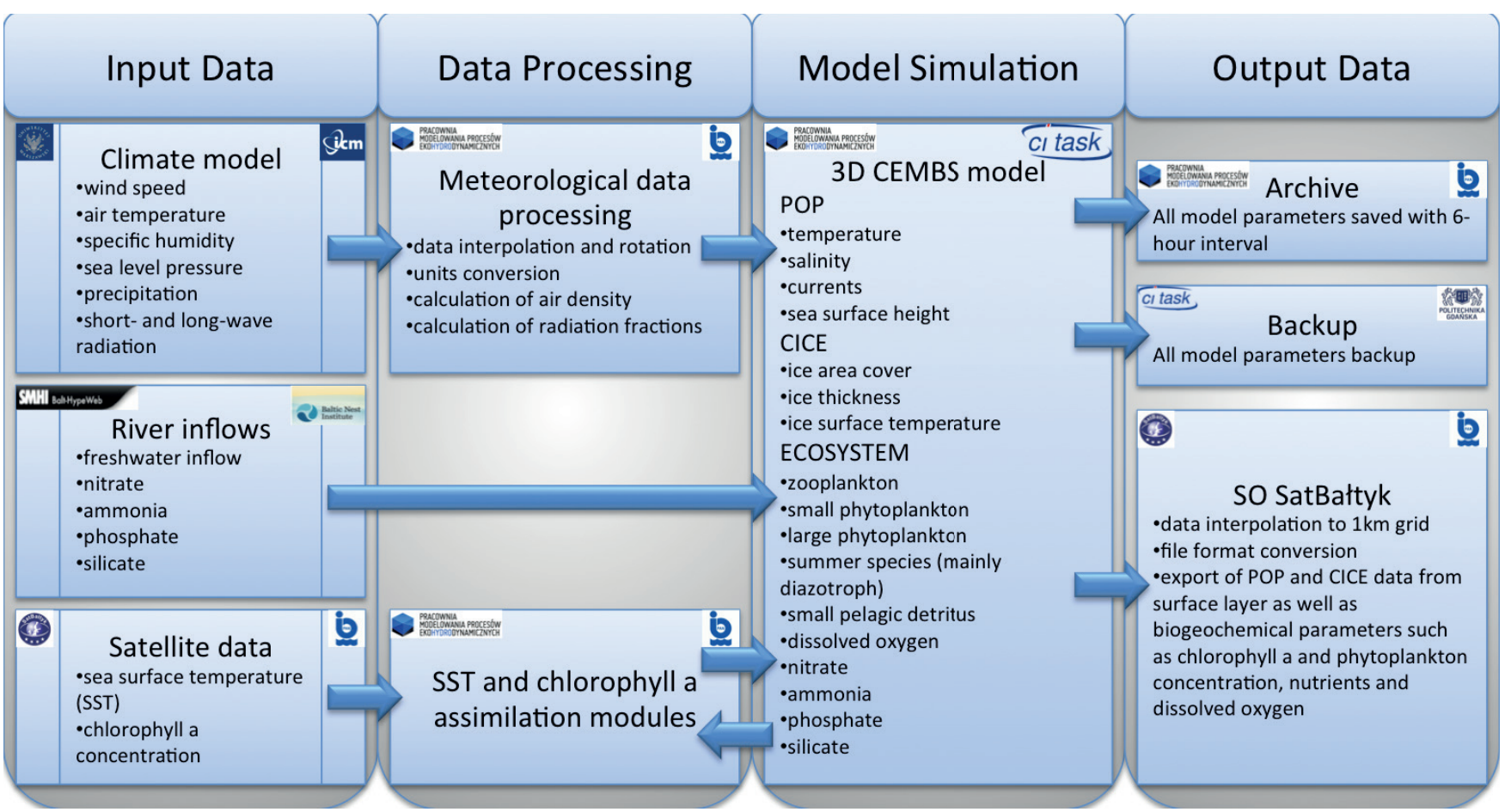

Fig. 4. Operational system block diagram

\section{ASSIMILATION SCHEME}

Data assimilation combines time- and space-distributed observations with a dynamic model. Satellite retrieved sea surface temperature (SST) from MODIS AQUA have been used in the temperature assimilation scheme. The level 0 raw satellite data from NASA Ocean Color Web have been processed within the standard msl12 SeaDAS code where satellite infrared MODIS bands 31 and 32 are corrected for atmospheric absorption using combinations of several MODIS mid- and far-infrared bands. ECMWF assimilation model of marine atmosphere with atmospheric properties and variability is supporting this correction. Cloud screening is based on two approaches: use of the cloud screening product (3660) and a cloud indicator derived during the SST retrieval. Data spatial resolution is around $1 \mathrm{~km}$. Accuracy of the retrieved SST can be considered to +/- 0.4 degrees Celsius.

$3 \mathrm{D}$ CEMBS is designed to work in an operational mode, therefore assimilation algorithm used in the system must be accurate, yet time efficient. Data assimilation scheme proposed by Cressman is relatively simple and computationally fast, whilst remaining accurate. Thus, it seems to be an appropriate choice. Scheme implemented in presented system is sequential, meaning that only data measured in the past until the time of analysis are used. It is also intermitted, which means that the assimilated information is processed in a single small batch, which is technically easier to implement as in opposite to continuous methods. Main disadvantage of this method is possibility of obtaining unrealistic results near the edge of the spatial domain. However, such extrema were not observed in the obtained results. The Cressman assimilation scheme can be described in the following steps. Results of the previous model's forecast are used as a background state $\mathrm{xb}$. Satellite data are then checked for errors and stored in the observations matrix $y$. Then for every grid-point $\mathrm{j}$ the analysis result $\mathrm{xa}$ is calculated based on the following equation:

$$
\mathrm{x}_{\mathrm{a}}(\mathrm{j})=\mathrm{x}_{\mathrm{b}}(\mathrm{j})+\frac{\sum_{\mathrm{i}=1}^{\mathrm{n}} \mathrm{w}(\mathrm{i}, \mathrm{j})\left\{\mathrm{y}(\mathrm{i})-\mathrm{x}_{\mathrm{b}}(\mathrm{i})\right\}}{\sum_{\mathrm{i}=1}^{\mathrm{n}} \mathrm{w}(\mathrm{i}, \mathrm{j})+\mathrm{E}^{2}}
$$

$\mathrm{E}$ is an estimate of the ratio of the observation error to the model error, $i$ and $j$ are satellite and model grid-points respectively. Weight function $\mathrm{w}$ depends on influence radius $\mathrm{R}$ and distance $\mathrm{d}$ between model and satellite results. It is defined as follows:

$$
w(i, j)=\max \left(0, \frac{R^{2}-d_{i, j}^{2}}{R^{2}+d_{i, j}^{2}}\right)
$$

The result of the analysis is then used as an initial state for the next forecast.

Similar scheme was used in case of satellite measured sea surface chlorophyll a concentration. However, chlorophyll a concentration obtained from the model is calculated based on its values in three groups of phytoplankton: large phytoplankton (mainly diatoms) small phytoplankton, and summer species (mainly cyanobacteria). Therefore, sum of these components is used for further calculations. Since chlorophyll a concentration has a log-normal distribution, logarithms of model and satellite determined values are used in the scheme. Therefore, the equation (1) is transformed to the following form:

$$
\log x_{a}(j)=\log x_{b}(j)+\frac{\sum_{i=1}^{n} w(i, j) \log \frac{y(i)}{x_{b}(i)}}{\sum_{i=1}^{n} w(i, j)+\varepsilon_{i, j}^{2}}
$$


In the above equation:

$$
\begin{gathered}
\varepsilon_{\mathrm{i}, \mathrm{j}} \sim \frac{x_{\mathrm{s}}(\mathrm{i})}{x_{\mathrm{m}}(\mathrm{j})}, \\
x=10^{\sigma \log }, \\
\sigma_{\log }=\mathrm{SD}\left(\log \frac{\mathrm{X}_{\mathrm{s}}(\mathrm{i})}{\mathrm{X}_{\mathrm{m}}(\mathrm{i})}\right)
\end{gathered}
$$

SD stands for standard deviation, subscripts $\mathrm{s}$ and $\mathrm{m}$ stand for satellite and model respectively, $\mathrm{X}$ are values of chlorophyll a concentration. Determined this way differences are then distributed between the three groups of phytoplankton, on the basis of their percentage of the total chlorophyll a concentration.

\section{RESULTS AND DISCUSSION}

The model with satellite-measured SST assimilation was calibrated and tested on data from years 2011-2012. In order to assess the impact of assimilation, the results of model with and without assimilation were then compared with in-situ measurements. [8]. After receiving satisfactory results the model was launched in the operational mode. To confirm the effectiveness of the assimilation algorithm another statistical comparison between both models and in-situ data was carried out based on data from year 2013. Parameters such as absolute mean error (systematic) $<\varepsilon>$ and root mean square error RMSE were calculated. Correlation coefficient $\mathrm{R}$ before and after removal of mean seasonal signal was also calculated. Table I contains the results of this comparison. As one can see the results calculated by the assimilating model are better.

Tab. 1. Statistical comparison of not assimilated and assimilated surface temperature

\begin{tabular}{|c|c|c|c|}
\hline Model type & R with/without mean signal & $<\varepsilon>\left[\mathrm{C}^{\circ}\right]$ & \left.${\text { RMSE }\left[\mathrm{C}^{\circ}\right]}^{\circ}\right]$ \\
\hline not assimilated & $0.966 / 0.60$ & -1.2 & 1.9 \\
\hline assimilated & $0.977 / 0.79$ & -0.10 & 1.4 \\
\hline
\end{tabular}

Systematic error decreased from $-1.2^{\circ} \mathrm{C}$ to only $-0.1^{\circ} \mathrm{C}$. Root mean square error with data assimilation is almost $25 \%$ smaller than that calculated for the model without data assimilation. The correlation coefficient of data before removal of mean signal is only slightly better. However, after removal of mean signal the difference increases significantly. This means that the changes, driven by the annual cycles are well represented by the model itself, but the assimilation allows better representation of local and short term anomalies. Fig. 5 shows the correlation of not assimilated (black) and assimilated (red) model results (x axis) with the in-situ measurements (y axis). In-situ data used for this comparison were obtained from fixed and non-fixed HELCOM stations and cover measurements of surface layer $(0-5 \mathrm{~m})$ temperature carried out in 2013. This plot shows that assimilated data are better correlated with in-situ measurements. The results are very comparable to those obtained from previous comparison calculated for years 2011-2012. This is a very good example of how applying even such a simple method of satellite data assimilation can significantly improve accuracy and quality of modelling results.

In October 2014 operational version of the model was suspended due to implementation of chlorophyll a concentration assimilation algorithms. Currently system is in the testing phase, however, first trial runs show promising results. Table II presents statistical comparison that shows, how assimilation of satellite-measured chlorophyll a concentration improved model's accuracy. However, these are still early results and some issues are still to be solved. Therefore more tests and longer trial runs must be performed before applying developed technique to the operational system.

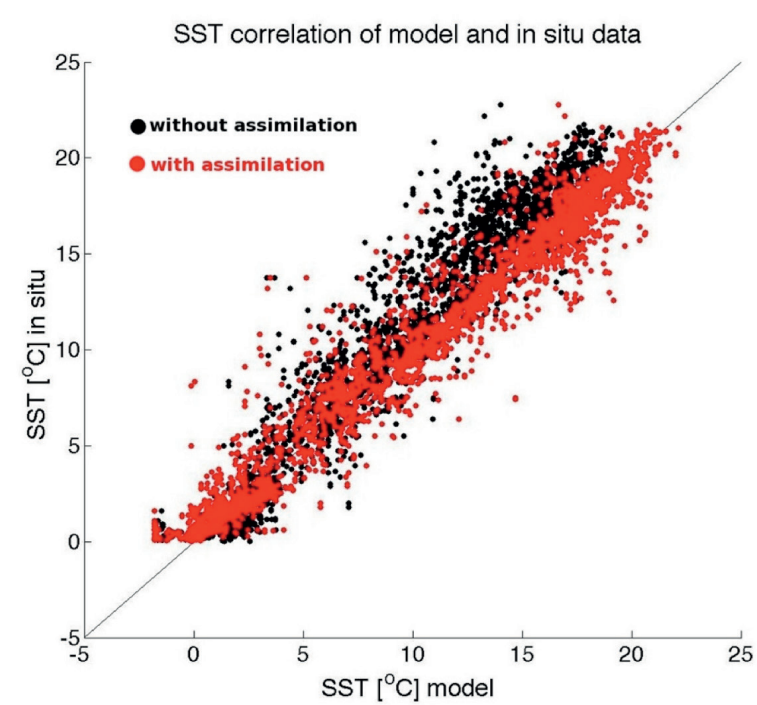

Fig. 5. Correlation of not assimilated and assimilated temperature results from year 2013

Tab. 2. Statistical comparison of not assimilated and assimilated chlorophyll a concentration

\begin{tabular}{|c|c|c|c|c|}
\hline \multirow{2}{*}{ Model type } & $\begin{array}{c}\text { Mean systematic } \\
\text { error }\end{array}$ & Error factor & $\begin{array}{c}\text { Upper limit of the } \\
\text { statistical error }\end{array}$ & $\begin{array}{c}\text { Lower limit of the } \\
\text { statistical error }\end{array}$ \\
\cline { 2 - 5 } & $<\varepsilon>_{\mathrm{g}}[\%]$ & $\mathrm{x}$ & $\sigma-[\%]$ & $\sigma+[\%]$ \\
\hline not assimilated & $-72.56 \%$ & 3.00 & $199.62 \%$ & $-66.62 \%$ \\
\hline assimilated & $-66.82 \%$ & 2.76 & $176.14 \%$ & $-63.79 \%$ \\
\hline
\end{tabular}

\section{ACKNOWLEDGEMENT}

The partial support for this study was provided by the project Satellite Monitoring of the Baltic Sea Environment - SatBałtyk founded by European Union through European Regional Development Fund contract no. POIG 01.01.02-22-011/09

The computing presented in this paper was carried out on the Galera super computer at the Academic Computer Centre in Gdansk (CI TASK). 
In-situ data used for validation were obtained from ICES Dataset on Ocean Hydrography. The International Council for the Exploration of the Sea Copenhagen. 2011, http://ocean.ices.dk/helcom/Helcom.aspx

\section{REFERENCE}

1. Brown O.B., Minnett P.J.: MODIS Infrared Sea Surface Temperature Algorithm Theoretical Basis Document, Ver 2.0, 1999, http://modis.gsfc.nasa.gov/data/atbd/atbd_ $\bmod 25 . \mathrm{pdf}$

2. Cressman G. P.: An operational objective analysis system, Monthly Weather Review 87 (1959) 367-374

3. Hunke E. C., Dukowicz J. K.: An elastic-viscous-plastic model for sea ice dynamics, J. Phys. Oceanogr. 27 (1997) 1849-1867

4. Dzierzbicka-Głowacka L., Jakacki J., Janecki M., Nowicki A.: Activation of the operational ecohydrodynamic model (3D CEMBS) - the hydrodynamic part, Oceanologia 55(3) (2013a) 519-541

5. Dzierzbicka-Głowacka L., Janecki M., Nowicki A., Jakacki J.: Activation of the operational ecohydrodynamic model (3D CEMBS) - the ecosystem module, Oceanologia 55(3) (2013a) 543-572

6. Dzierzbicka-Głowacka L., Nowicki A., Janecki M.: The automatic monitoring system for 3D CEMBSv2 in operational Version, Journal of Environmental Science and Engineering Technology 1 (2014) 1-9

7. Moore J. K., Doney S. C., Kleypas J. A., Glover D. M., Fung I. Y.: An intermediate complexity marine ecosystem model for the global domain, Deep-Sea Res. II,49 (2002) 403-462.

8. Nowicki A., Dzierzbicka-Głowacka L., Janecki M., Kałas M.: Assimilation of the satellite SST data in the 3D CEMBS model, Oceanologia 57(1) (2015) 17-24

9. Smith R., Gent P.: Reference manual for the Parallel Ocean Program (POP), New Mexico, Los Alamos National Lab, 2004, pp. 75

10. Woźniak B., Bradtke K., Darecki M., Dera J., DudzińskaNowak J., Dzierzbicka-Głowacka L., Ficek D., Furmańczyk K., Kowalewski M., Krężel A., Majchrowski R., Ostrowska M., Paszkuta M., Stoń-Egiert J., Stramska M., Zapadka T.: SatBałtyk - A Baltic environmental satellite remote sensing system - an ongoing project in Poland. Part 1: Assumptions, scope and operating range, Oceanologia 53(4) (2011a) 897-924
11. Woźniak B., Bradtke K., Darecki M., Dera J., DudzińskaNowak J., Dzierzbicka-Głowacka L., Ficek D., Furmańczyk K., Kowalewski M., Krężel A., Majchrowski R., Ostrowska M., Paszkuta M., Stoń-Egiert J., Stramska M., Zapadka T.: SatBałtyk - A Baltic environmental satellite remote sensing system - an ongoing project in Poland. Part 2: Practical applicability and preliminary results, Oceanologia 53(4) (2011a) 925-958

\section{CONTACT WITH AUTHOR}

\author{
Lidia Dzierzbicka-Głowacka \\ Institute of Oceanology \\ Polish Academy of Sciences \\ 55 Powstańców Warszawy St. \\ 81-712 Sopot \\ Poland
}

e-mail: dzierzb@iopan.gda.pl 